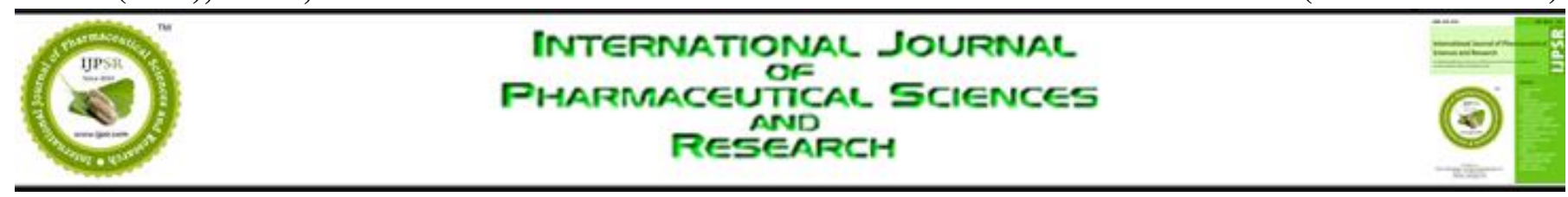

Received on 25 October, 2016; received in revised form, 09 December, 2016; accepted, 16 December, 2016; published 01 May, 2017

\title{
A NEW VALIDATED RP-HPLC METHOD FOR THE DETERMINATION OF METFORMIN HCL AND EMPAGLIFLOZIN IN ITS BULK AND PHARMACEUTICAL DOSAGE FORMS
}

\author{
S. K. Godasu * and S. A. Sreenivas
}

Mewar University, Chittorgarh, Rajasthan, India.

Keywords:

Metformin, Empagliflozin, HPLC, Methanol

\section{Correspondence to Author:}

\section{S. K. Godasu}

Research scholar,

Mewar University

Assistant Professor, Sree dattha

Institute of Pharmacy, Sheriguda, Ibrahim, Patnam Ranga reddy,

501510, Telangana, India.

E-mail: suresh.niper12@gmail.com

\begin{abstract}
A New method was established for simultaneous estimation of Metformin and Empagliflozin by RP-HPLC method. The chromatographic conditions were successfully developed for the separation of Metformin and Empagliflozin by using Symmetry C18 column $(4.6 \times 150 \mathrm{~mm}) 5 \mu$, flow rate was $1 \mathrm{ml} / \mathrm{min}$, mobile phase ratio was $(70: 30 \mathrm{v} / \mathrm{v})$ methanol: phosphate buffer $\left(\mathrm{KH}_{2} \mathrm{PO}_{4}\right.$ and $\left.\mathrm{K}_{2} \mathrm{HPO}_{4}\right)$ phosphate $\mathrm{pH} \quad 3 \quad(\mathrm{pH}$ was adjusted with orthophosphoricacid), detection wavelength used was Waters HPLC Auto Sampler, Separation module 2695, photo diode array detector 996, Empower-software version-2. The retention times were found to be $2.403 \mathrm{mins}$ and $3.907 \mathrm{mins}$. The $\%$ purity of Metformin and Empagliflozin was found to be $99.87 \%$ and $100.27 \%$ respectively. The analytical method was validated according to $\mathrm{ICH}$ guidelines (ICH, Q2 (R1). The linearity study of Metformin and Empagliflozin was found in concentration range of $50 \mu \mathrm{g}-250 \mu \mathrm{g}$ and $5 \mu \mathrm{g}-25 \mu \mathrm{g}$ and correlation coefficient $\left(\mathrm{r}^{2}\right)$ was found to be 0.999 and 0.999 , \% recovery was found to be $99.56 \%$ and $99.48 \%$, \%RSD for repeatability was 0.3 and 0.3 , \% RSD for intermediate precision was 1.3 and 0.4 respectively. LOD value was 2.17 and 0.0372 and LOQ value was 6.60 and 0.1125 respectively.
\end{abstract}

INTRODUCTION: Empagliflozin is a drug of the gliflozin class, approved for the treatment of type 2 diabetes in adults in 2014. The chemical name of empagliflozin is (empagliflozin; 1-chloro-4-[b-Dglucopyranos-1-yl]-2-[4-([S]-tetrahydrofuran - 3 yl -oxy) benzyl]-benzene (Fig. 1). Empagliflozin is an inhibitor of the sodium glucose co-transporter-2 (SGLT-2), which is found almost exclusively in the proximal tubules of nephronic components in the kidneys ${ }^{1}$.SGLT-2 accounts for about 90 percent of glucose reabsorption into the blood. Blocking SGLT-2 reduces blood glucose by blocking glucose reabsorption in the kidney and thereby excreting glucose (i.e., blood sugar) via the urine.

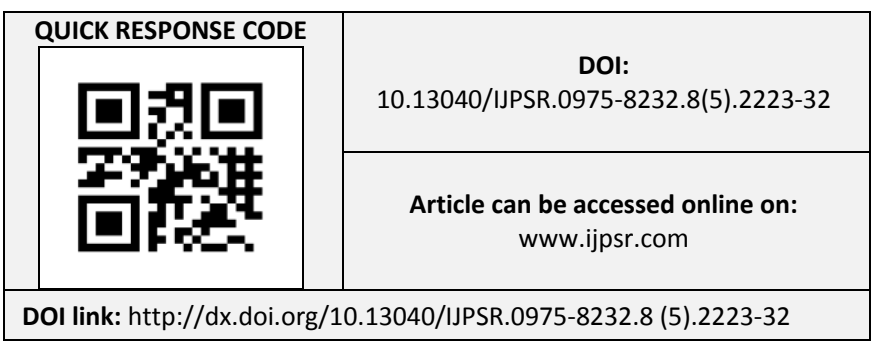

The side effects of this drug is a higher frequency of urinary tract infections. There are concerns it may increase the risk of diabetic ketoacidosis. Metformin is a biguanide antihyperglycemic agent used for treating non-insulin-dependent diabetes mellitus (NIDDM) ${ }^{3}$. The chemical name of Metformine Dimethylimidodicarbonimidic diamide (Fig. 2).

It improves glycemic control by decreasing hepatic glucose production, decreasing glucose absorption and increasing insulin-mediated glucose uptake ${ }^{4}$ Metformin is the only oral antihyperglycemic agent that is not associated with weight gain. Metformin may induce weight loss and is the drug of choice for obese NIDDM patients.

When used alone, metformin does not cause hypoglycemia; however, it may potentiate the hypoglycemic effects of sulfonylureas and insulin. Its main side effects are dyspepsia, nausea and diarrhea ${ }^{5}$. 


\section{FIG. 1: STRUCTURE OF EMPAGLIFLOZIN}

\section{FIG. 2: STRUCTURE OF METFORMINE}

Various analytical methods were reported in literature for the determination of empagliflozin and metformin in pure drug, pharmaceutical dosage forms and in biological samples using High performance liquid chromatography 7-12, High performance thin layer chromatography ${ }^{13-14}$, UVSpectrophotometry ${ }^{15-17}$, Ultra performance liquid chromatography ${ }^{18}$, either in single or in combined forms. Lack of any published method for RP-HPLC simultaneous estimation of Metformin and Empagliflozin in API, therefore, provoked us to investigate the application of method development and validation of RP-HPLC method for the simultaneous estimation of Metformin and Empagliflozin in API. The new method developed and validated for Metformin and Empagliflozin in its bulk and tablets will help as a research interest to formulate different advanced drug delivery dosage forms and further its analyses.

\section{MATERIALS AND METHODS:}

Instrumentation: The chromatography was performed on a Waters 2695 HPLC system, equipped with an auto sampler, PDA detector and Empower 2 software. Analysis was carried out at $240 \mathrm{~nm}$ with an Intersil C18, 150mmx40mm, $5 \mu \mathrm{m}$ ) dimensions at ambient temperature

Chemicals and reagents: Empagliflozin and Metformine were supplied as gift sample from Mylon laboratories, Hyderabad. $\mathrm{KH}_{2} \mathrm{PO}_{4}$ was analytical grade supplied by FINER chemical LTD, Mumbai, Orthophosphoric acid (Merck), Acetonitrile (Molychem, HPLC grade) and Water for HPLC (Lichrosolv (Merck).
Preparation of solutions:

Preparation of buffer: Accurately weighed 6.8 grams of KH2PO4 was taken in a $1000 \mathrm{ml}$ volumetric flask, dissolved and diluted to $1000 \mathrm{ml}$ with HPLC water and the volume was adjusted to $\mathrm{pH} 3.0$ with Orthophosphoric acid.

Preparation of mobile phase: Accurately measured $300 \mathrm{ml}(30 \%)$ of above buffer and 700 $\mathrm{ml}$ of Methanol HPLC (70\%) were mixed and degassed in an ultrasonic water bath for 10 minutes and then filtered through $0.45 \mu$ filter under vacuum filtration.

The diluents: The Mobile phase was used as the diluent.

Preparation of standard stock solution: Accurately weigh and transfer $1000 \mathrm{mg}$ of Metformin and10 $\mathrm{mg}$ of Empagliflozin working standard into a $100 \mathrm{ml}$ clean dry volumetric flask add about $70 \mathrm{~mL}$ of Diluent and sonicate to dissolve it completely and make volume up to the mark with the same solvent. (Stock solution) Further pipette $1.5 \mathrm{ml}$ of the above stock solutions into a $10 \mathrm{ml}$ volumetric flask and dilute up to the mark with diluent.(1500 ppm MET and 15 ppm of EMPA)

Preparation of Sample stock solution: Accurately weigh 10 tablets crush in mortor and pestle and transfer equivalent to $1000 \mathrm{mg}$ of Metformin and 10mg Empagliflozin (marketed formulation) sample into a $100 \mathrm{~mL}$ clean dry volumetric flask add about $70 \mathrm{~mL}$ of Diluent and sonicate to dissolve it completely and make volume up to the mark with the same solvent. (Stock solution) Further pipette $1.5 \mathrm{ml}$ of Metformine and Empagliflozin of the above stock solution into a $10 \mathrm{ml}$ volumetric flask and dilute up to the mark with diluent. (1500 ppm MET and $15 \mathrm{ppm}$ of EMPA).

Procedure: Inject $10 \mu \mathrm{L}$ of the standard, sample into the chromatographic system and measure the areas for Metformin and Empagliflozin peaks and calculate the \%Assay by using the formulae. 
Method development selection of wavelength: Stock solution of $100 \mathrm{mg} / \mathrm{ml}$ was prepared for Empagliflozin and Metformine further diluted to get the concentration of $10 \mu \mathrm{g} / \mathrm{ml}$ of Empagliflozin and Metformine was prepared with methanol. The wavelength was selected by scanning the above standard drug solution between 200 to $400 \mathrm{~nm}$. The scanned results showed that reasonable maximum absorbance was recorded at $240 \mathrm{~nm}$. Therefore $240 \mathrm{~nm}$ was selected as the detection wavelength for the RP-HPLC investigation Fig. 3.

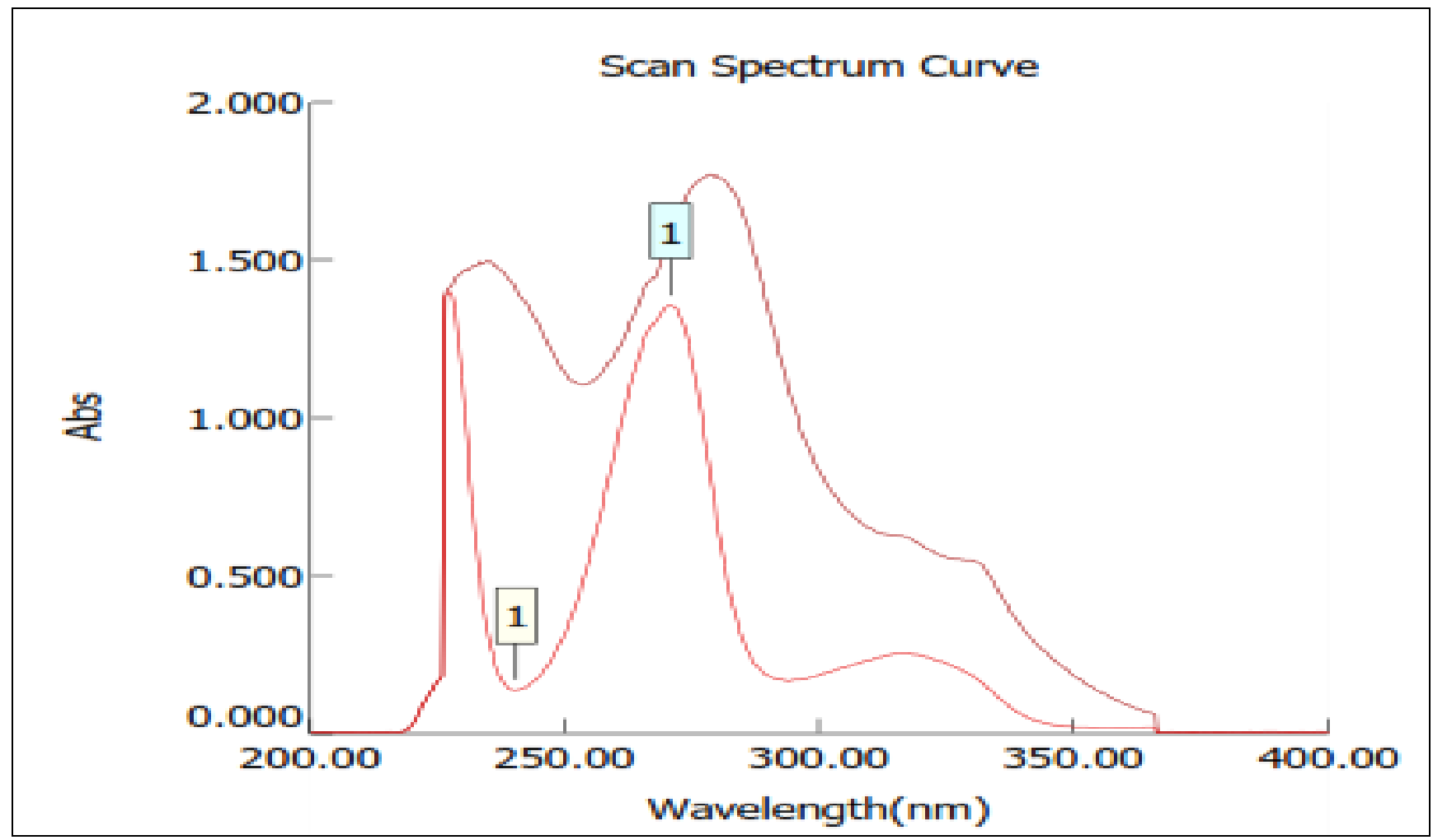

FIG. 3: UV SPECTRA OF EMPAGLIFLOZIN AND METFORMINE

Construction of calibration curve: Aliquots of different concentrations of standard solution were prepared and their chromatograms were recorded at the optimized chromatographic conditions. The mean peak areas at different concentration levels were calculated from the chromatograms. Then the linearity plot was constructed using the mean peak areas at their respective concentrations.

Method validation: The developed method was validated for linearity, accuracy, precision, and limit of detection, limit of quantitation, robustness and system suitability parameters as described in ICH guidelines.

Linearity: From the stock solution, 25, 50, 75, $100,125,150 \mu \mathrm{g} / \mathrm{ml}$ solutions were made and their chromatograms were recorded. From the recorded chromatograms, their respective mean peak areas were calculated and the linearity plot was constructed using the mean peak areas at their respective concentrations. The correlation coefficient was found to be 0.999 . The linearity data of Empagliflozin and Metformine was shown in Table 1 and Table 2, the calibration plot.

RESULTS AND DISCUSSION: The present investigation reported in the thesis was aimed to develop a new method development and validation for the simultaneous estimation of Metformin and Empogliflozin by RP-HPLC method. Literature reveals that there are no analytical methods reported for the simultaneous estimation Metformin and Empogliflozin by RP-HPLC method. Hence, it was felt that, there is a need of new analytical method development for the simultaneous estimation of Metformin and Empogliflozin in pharmaceutical dosage form. 


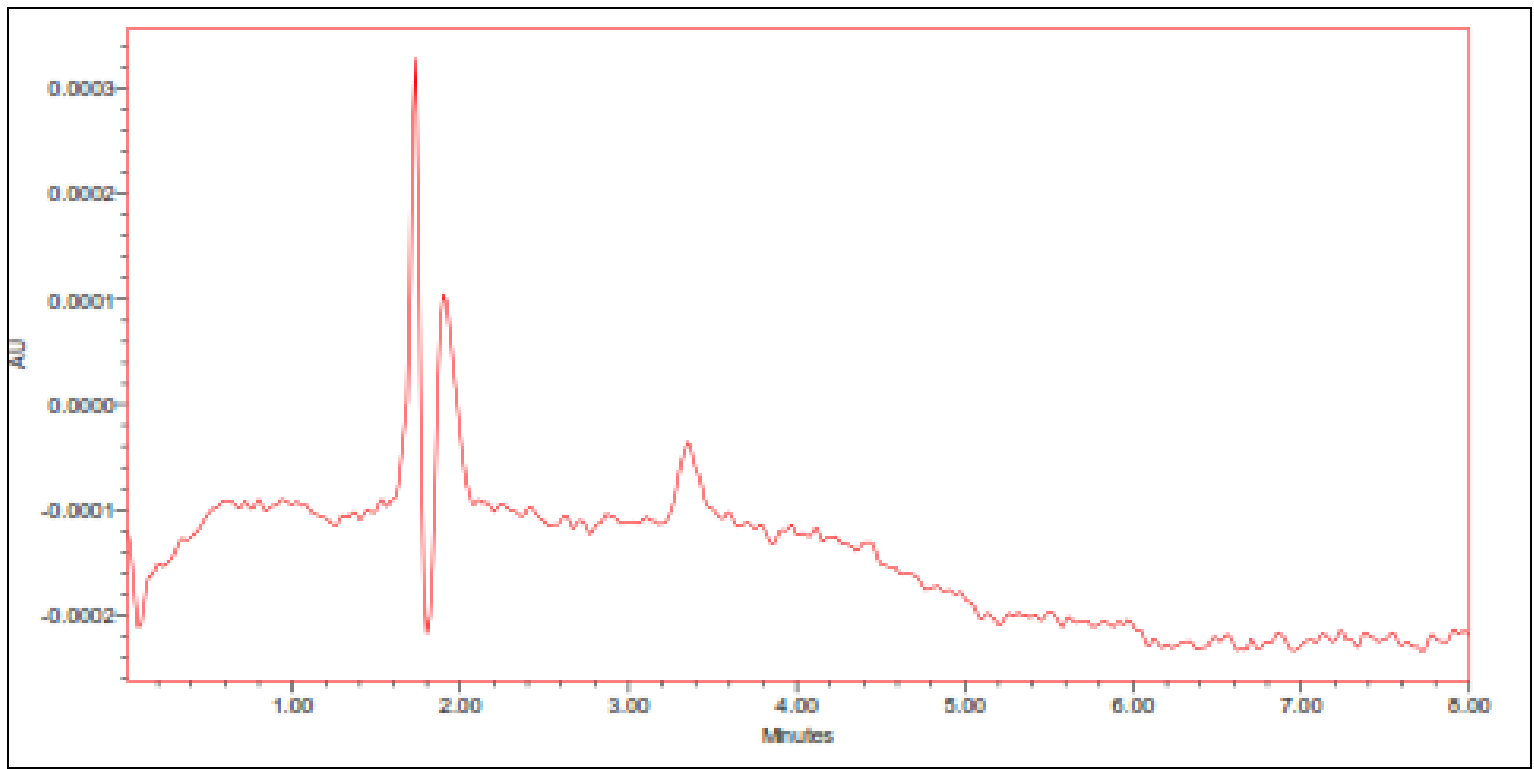

FIG. 4: CHROMATOGRAM SHOWING BLANK PREPARATION (MOBILE PHASE)

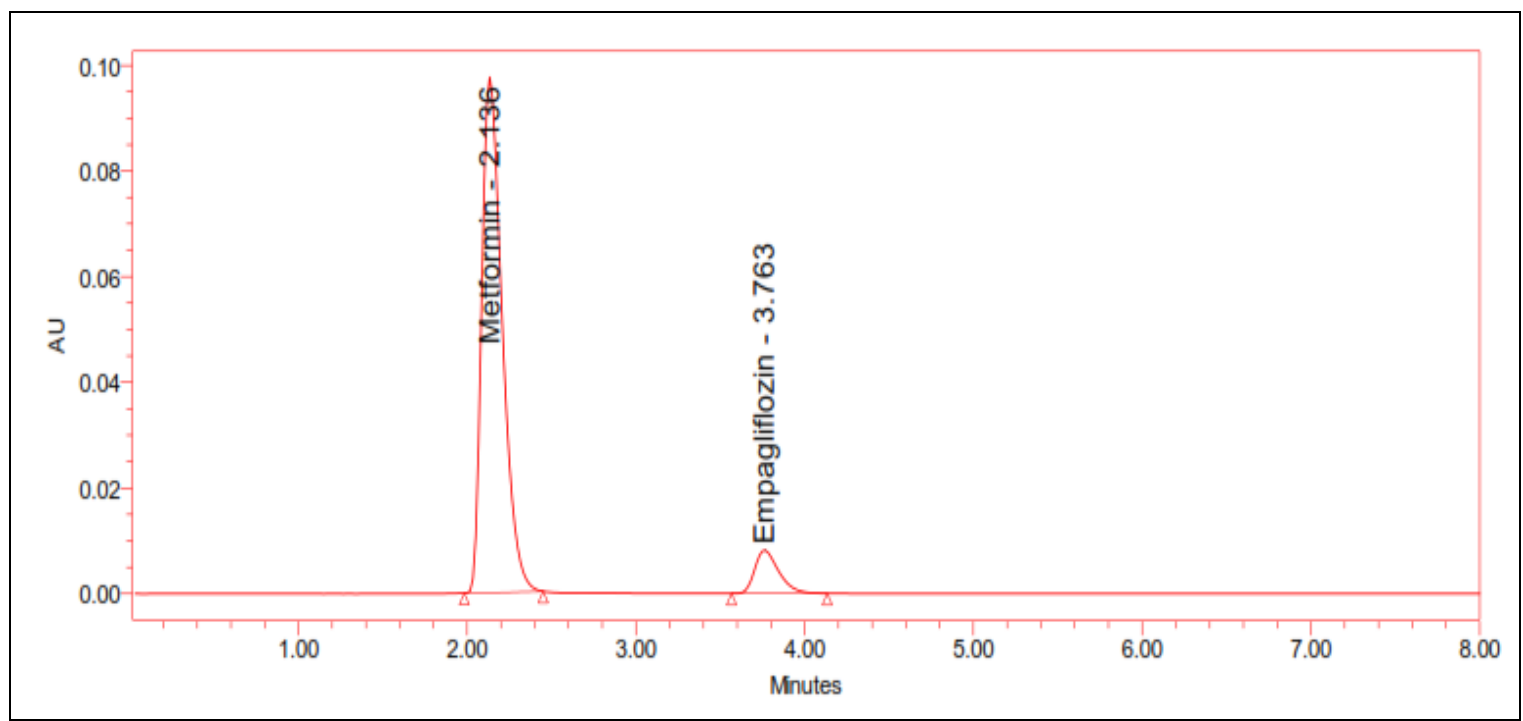

FIG. 5: CHROMATOGRAM SHOWING ASSAY OF SAMPLE INJECTION

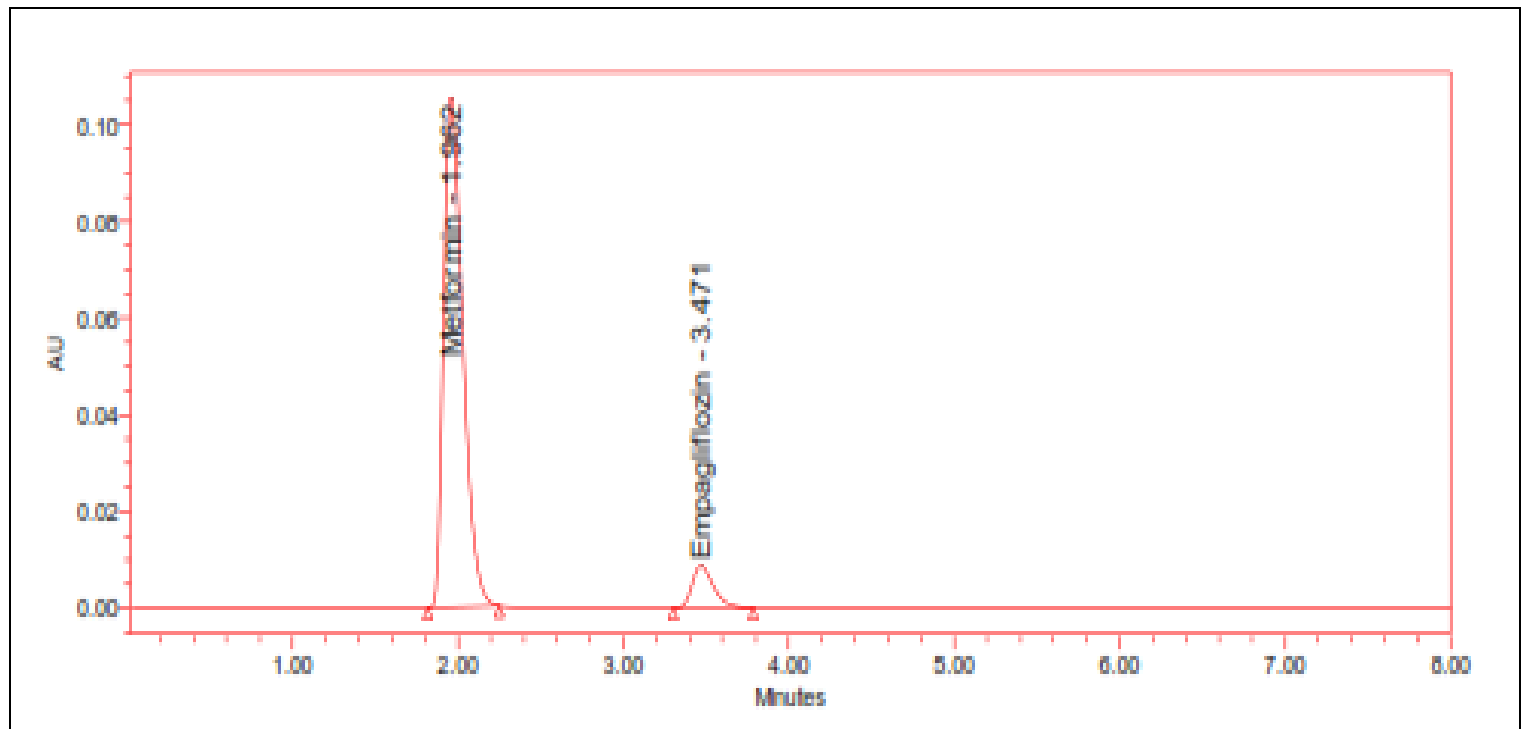

FIG. 6: CHROMATOGRAM SHOWING STANDARD OF SAMPLE INJECTION

International Journal of Pharmaceutical Sciences and Research 
TABLE 1: SHOWING ASSAY RESULTS

\begin{tabular}{cccc}
\hline S. no & Name of compound & Amount taken(mg) & \%purity \\
\hline 1 & Metformin & $1000 \mathrm{mg}$ & 98.21 \\
2 & Empogliflozin & $10 \mathrm{mg}$ & 100.47 \\
\hline
\end{tabular}

\section{Linearity:}

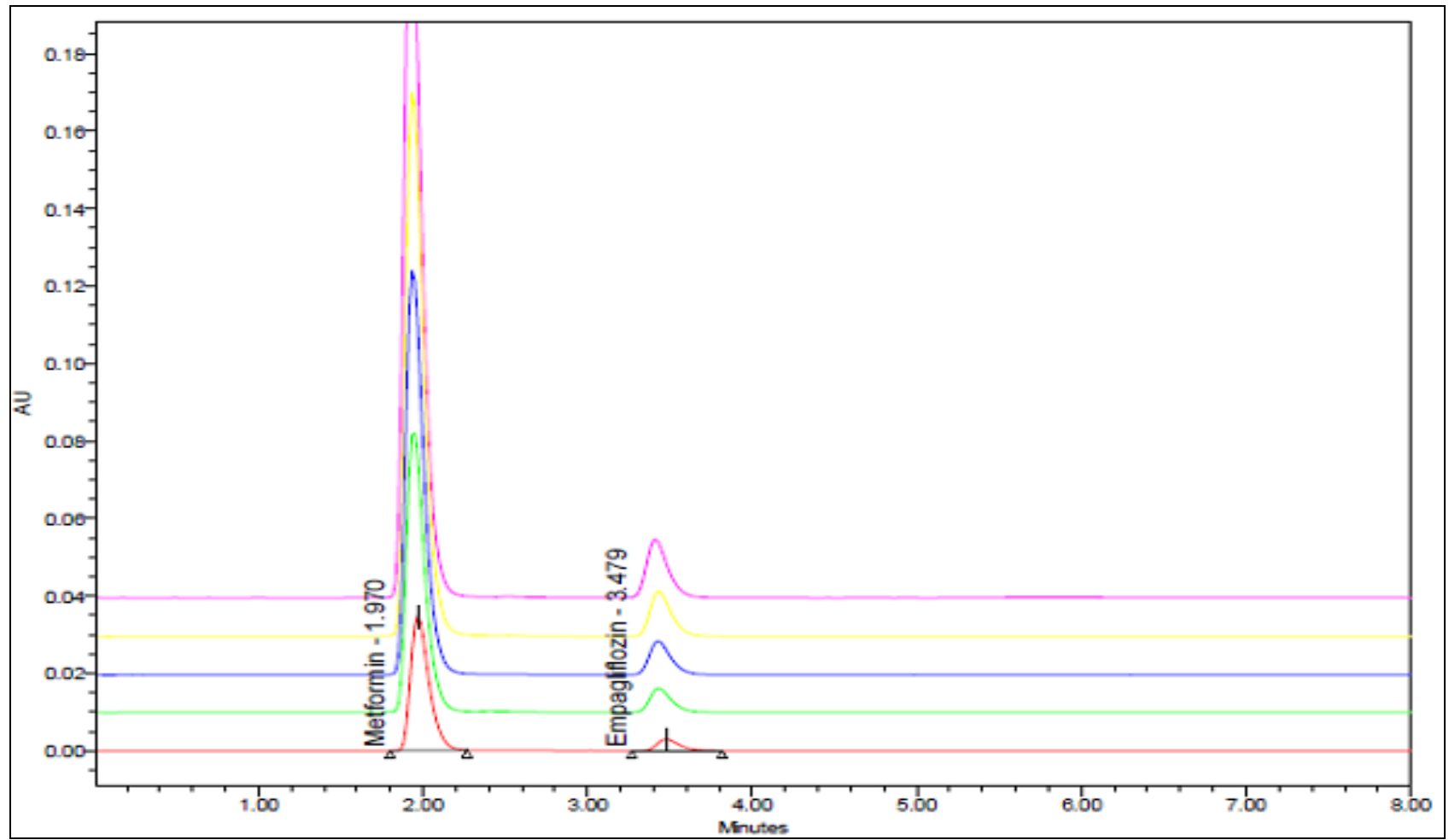

FIG. 7: CHROMATOGRAMS SHOWING LINEARITY OVERLAY

TABLE 2: LINEARITY RESULTS FOR METFORMINE

\begin{tabular}{cccc}
\hline S. No & Linearity Level & Concentration(ppm) & Area \\
\hline 1 & I & 500 & 270141 \\
2 & II & 1000 & 558098 \\
3 & III & 1500 & 798449 \\
4 & IV & 2000 & 1080708 \\
5 & V & 2500 & 1369144 \\
& Correlation Coefficient & & 0.999 \\
\hline
\end{tabular}

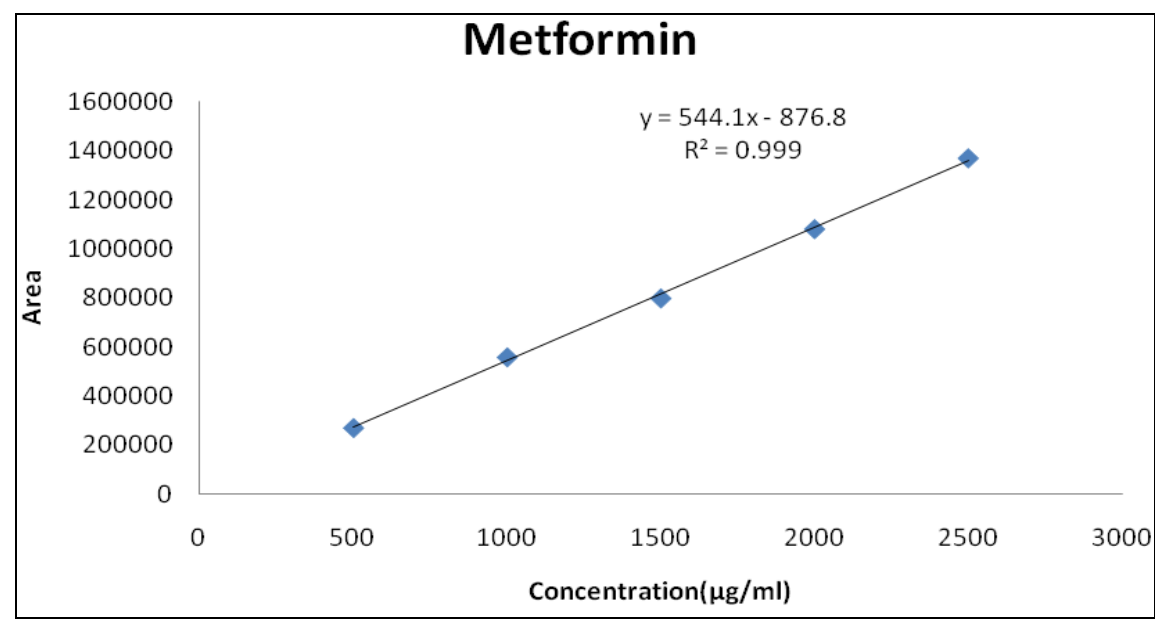

FIG. 8: SHOWING CALIBRATION GRAPH FOR METFORMINE

International Journal of Pharmaceutical Sciences and Research 
TABLE 3: LINEARITY RESULTS FOR EMPAGLIFLOZIN

\begin{tabular}{cccc}
\hline S. No & Linearity Level & Concentration(ppm) & Area \\
\hline 1 & I & 5 & 27213 \\
2 & II & 10 & 55506 \\
3 & III & 15 & 78707 \\
4 & IV & 20 & 105801 \\
5 & V & 25 & 133244 \\
& Correlation Coefficient & & 0.999 \\
\hline
\end{tabular}

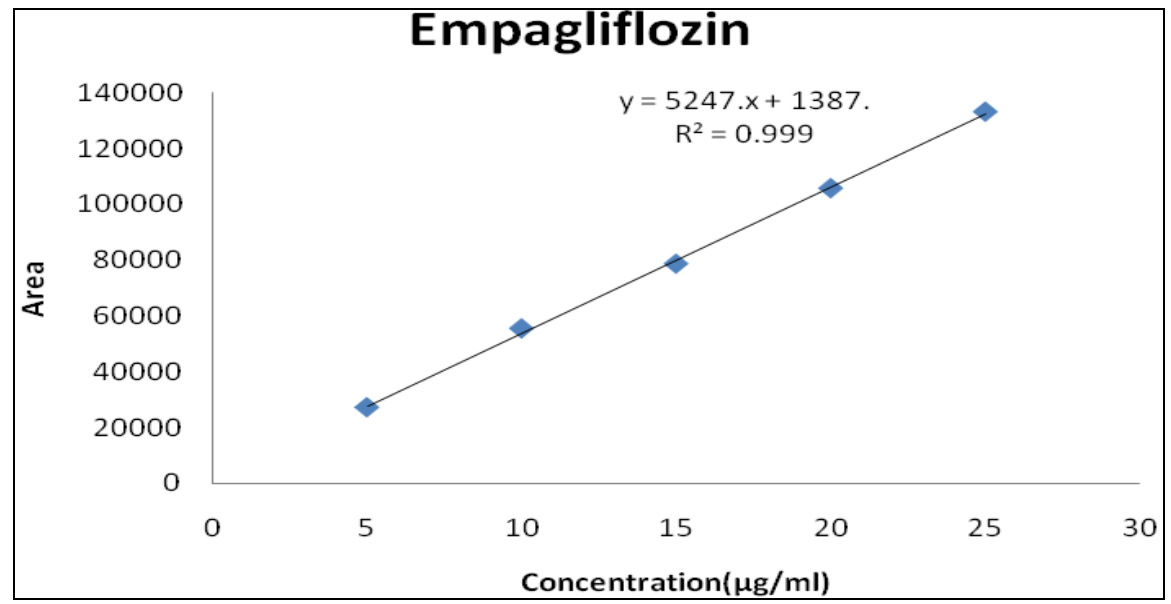

FIG. 9: SHOWING CALIBRATION GRAPH FOR EMPOGLIFLOZIN

Accuracy: The accuracy study was performed for into chromatographic system. The area of each leve $50 \%, 100 \%$ and $150 \%$ for Metformin and 1 was used for calculation of \% recovery.

Empogliflozin. Each level was injected in triplicate

TABLE 4: SHOWING ACCURACY RESULTS FOR METFORMIN

\begin{tabular}{cccccc}
\hline $\begin{array}{c}\text { \% Concentration } \\
\text { (at specification level) }\end{array}$ & $\begin{array}{c}\text { Average } \\
\text { Area }\end{array}$ & $\begin{array}{c}\text { Amount added } \\
(\mathbf{m g})\end{array}$ & $\begin{array}{c}\text { Amount found } \\
(\mathbf{m g})\end{array}$ & \% Recovery & $\begin{array}{c}\text { Mean } \\
\text { recovery }\end{array}$ \\
\hline $50 \%$ & 428731 & 75 & 74.96 & $99.91 \%$ & \\
$100 \%$ & 851297 & 150 & 149.98 & $99.18 \%$ & $99.56 \%$ \\
$150 \%$ & 1275904 & 225 & 224.02 & $99.60 \%$ & \\
\hline
\end{tabular}

TABLE 5: SHOWING ACCURACY RESULTS FOR EMPAGLIFLOZIN

\begin{tabular}{cccccc}
\hline $\begin{array}{c}\text { \% Concentration } \\
\text { (at specification level) }\end{array}$ & $\begin{array}{c}\text { Average } \\
\text { Area }\end{array}$ & $\begin{array}{c}\text { Amount added } \\
(\mathbf{m g})\end{array}$ & $\begin{array}{c}\text { Amount found } \\
(\mathbf{m g})\end{array}$ & \% Recovery & $\begin{array}{c}\text { Mean } \\
\text { recovery }\end{array}$ \\
\hline $50 \%$ & 40731 & 25 & 24.99 & $99.53 \%$ & \\
$100 \%$ & 82456 & 50 & 49.05 & $99.38 \%$ & $99.47 \%$ \\
$150 \%$ & 122414 & 75 & 74.495 & $99.52 \%$ & \\
\hline
\end{tabular}

The accuracy study was performed for \% recovery was found to be $99.18 \%$ and $99.91 \%$ respectively of Metformin and Empogliflozin. The \% recovery (NLT 98\% and NMT 102\%)

\section{Precision:}

TABLE 6: SHOWING\% RSD RESULTS FOR METFORMIN AND EMPAGLIFLOZIN

\begin{tabular}{ccccc}
\hline S.no. & \multicolumn{2}{c}{ Metformine } & \multicolumn{2}{c}{ Empagliflozin } \\
\cline { 2 - 5 } & RT & Area & RT & Area \\
\hline 1 & 1.956 & 829858 & 3.457 & 81017 \\
2 & 1.962 & 824838 & 3.471 & 79440 \\
3 & 1.980 & 834631 & 3.501 & 81571 \\
4 & 1.992 & 845317 & 3.523 & 81704 \\
5 & 1.996 & 849490 & 3.557 & 82457 \\
6 & 2.002 & 841368 & 3.562 & 82471 \\
Mean & & 837583.7 & & 81443.3 \\
\hline
\end{tabular}




\begin{tabular}{ccc}
\hline Std. Dev & 9452.4 & 1128.1 \\
$\%$ RSD & 1.1 & 1.4 \\
\hline
\end{tabular}

Intermediate precision/Ruggedness:

TABLE 7: SHOWING RESULTS FOR INTERMEDIATE PRECISION OF METFORMIN AND EMPAGFLIFLOZIN

\begin{tabular}{ccccc}
\hline S.no. & \multicolumn{2}{c}{ Metformine } & \multicolumn{2}{c}{ Empagliflozin } \\
\cline { 2 - 5 } & RT & Area & RT & Area \\
\hline 1 & 1.910 & 854596 & 3.368 & 83674 \\
2 & 1.921 & 864089 & 3.387 & 84042 \\
3 & 1.926 & 852527 & 3.400 & 83222 \\
4 & 1.931 & 857218 & 3.407 & 83523 \\
5 & 1.940 & 862365 & 3.426 & 83218 \\
6 & 1.946 & 845558 & 3.435 & 82581 \\
Mean & & 856058.7 & & 83376.4 \\
Std. Dev & & 6789.4 & & 497.0 \\
\% RSD & & 0.8 & & 0.6 \\
\hline
\end{tabular}

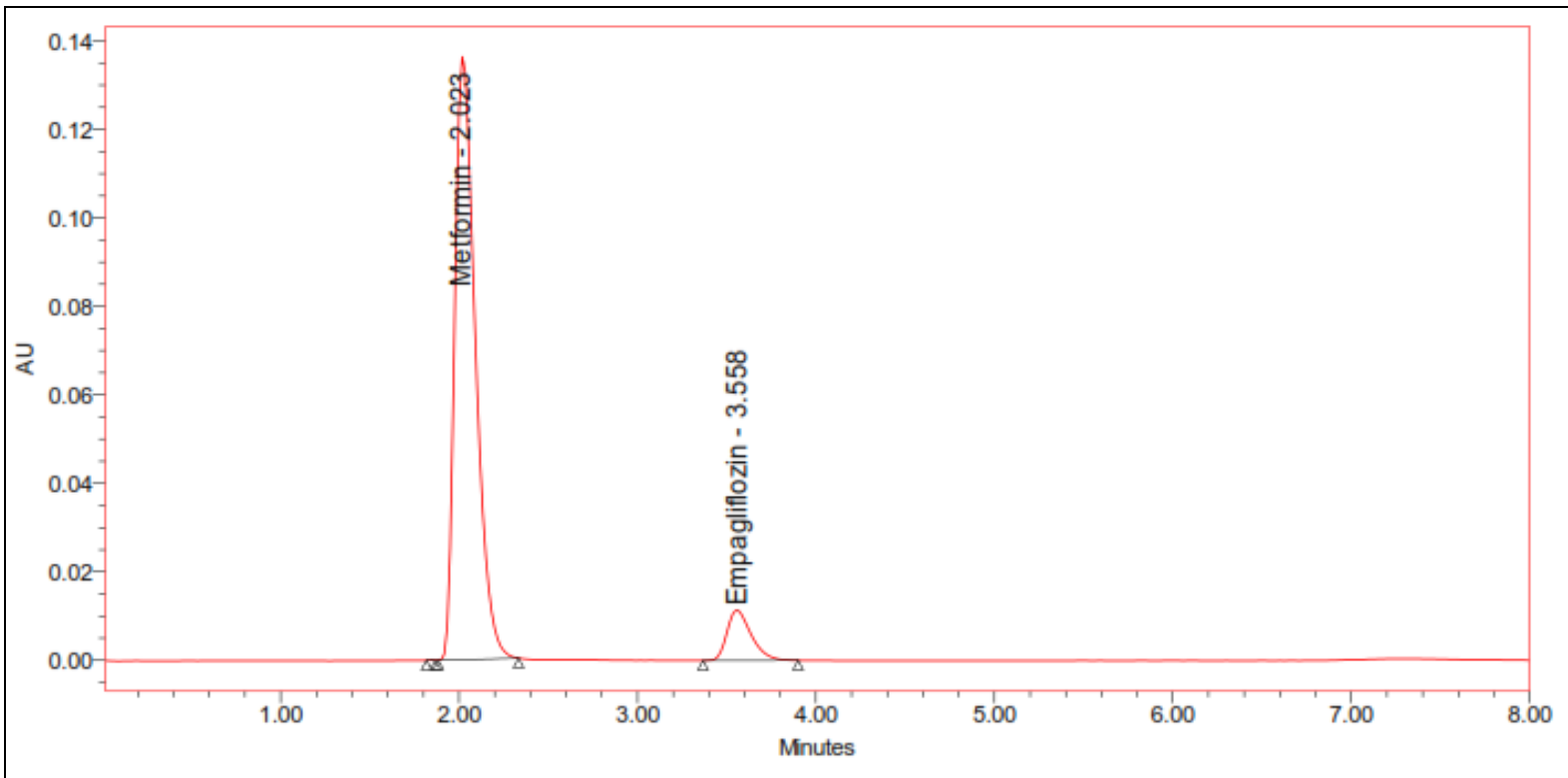

FIG. 10: CHROMATOGRAM SHOWING LESS FLOW

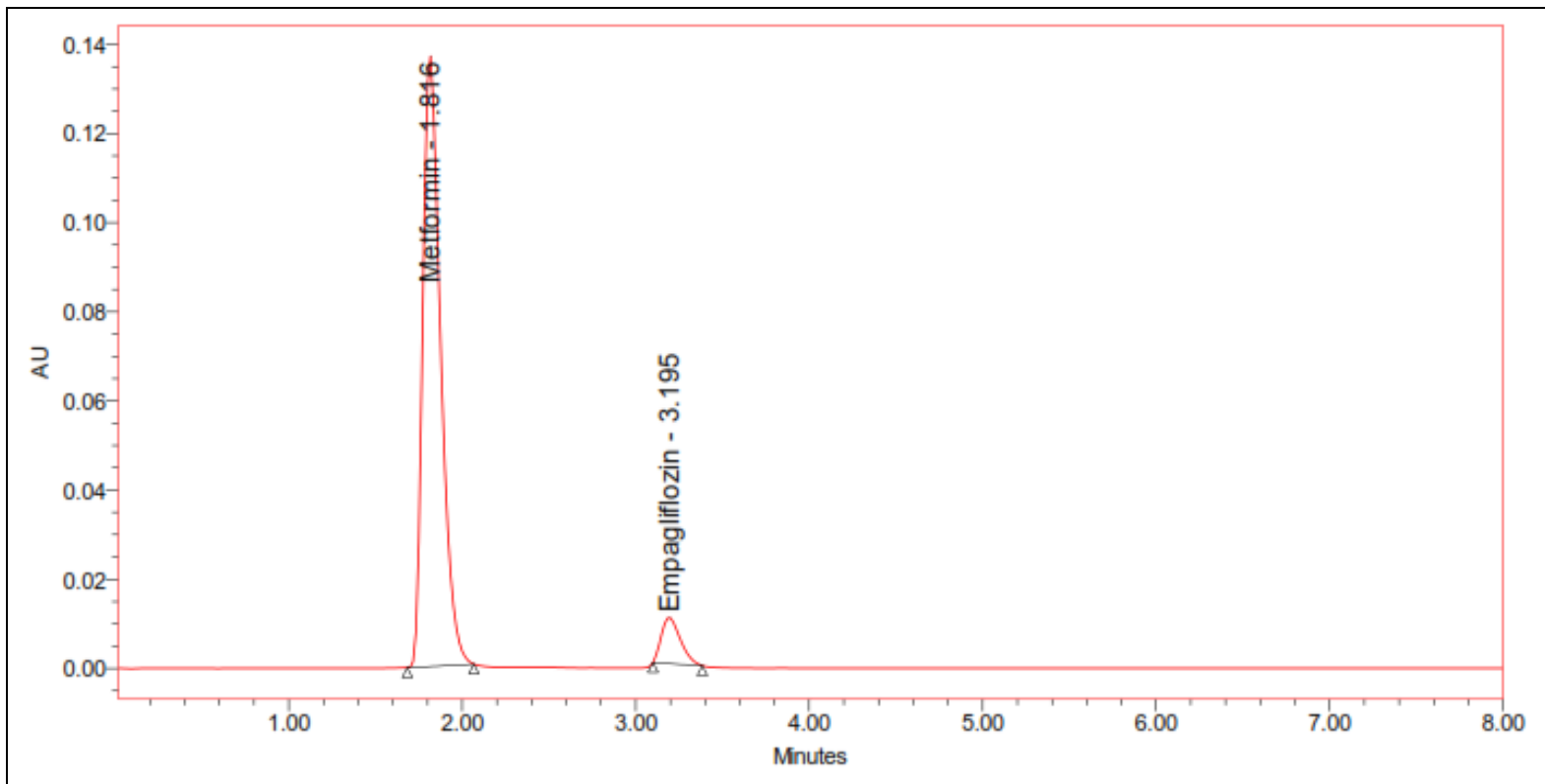

FIG. 11: CHROMATOGRAM SHOWING MORE FLOW

International Journal of Pharmaceutical Sciences and Research 
TABLE 8: SYSTEM SUITABILITY RESULTS FOR METFORMIN

S. no.

Flow Rate (ml/min)

1

1.0

1.2
System Suitability Results

\section{USP Plate Count}

2418.2

2415.75

2424.1
USP Tailing

1.5

1.43

1.4

TABLE 9: SYSTEM SUITABILITY RESULTS FOR EMPAGLIFLOZIN

S. no.

Flow Rate (ml/min)

USP Plate Count

* Results

$\begin{array}{ll}1 & 0.8 \\ 2 & 1.0 \\ 3 & 12\end{array}$

1.0

1.2

3318.5

3310.51

3698.9

System Suitability Results

* Results for actual flow (1.0ml/min) have been considered from Assay standard.

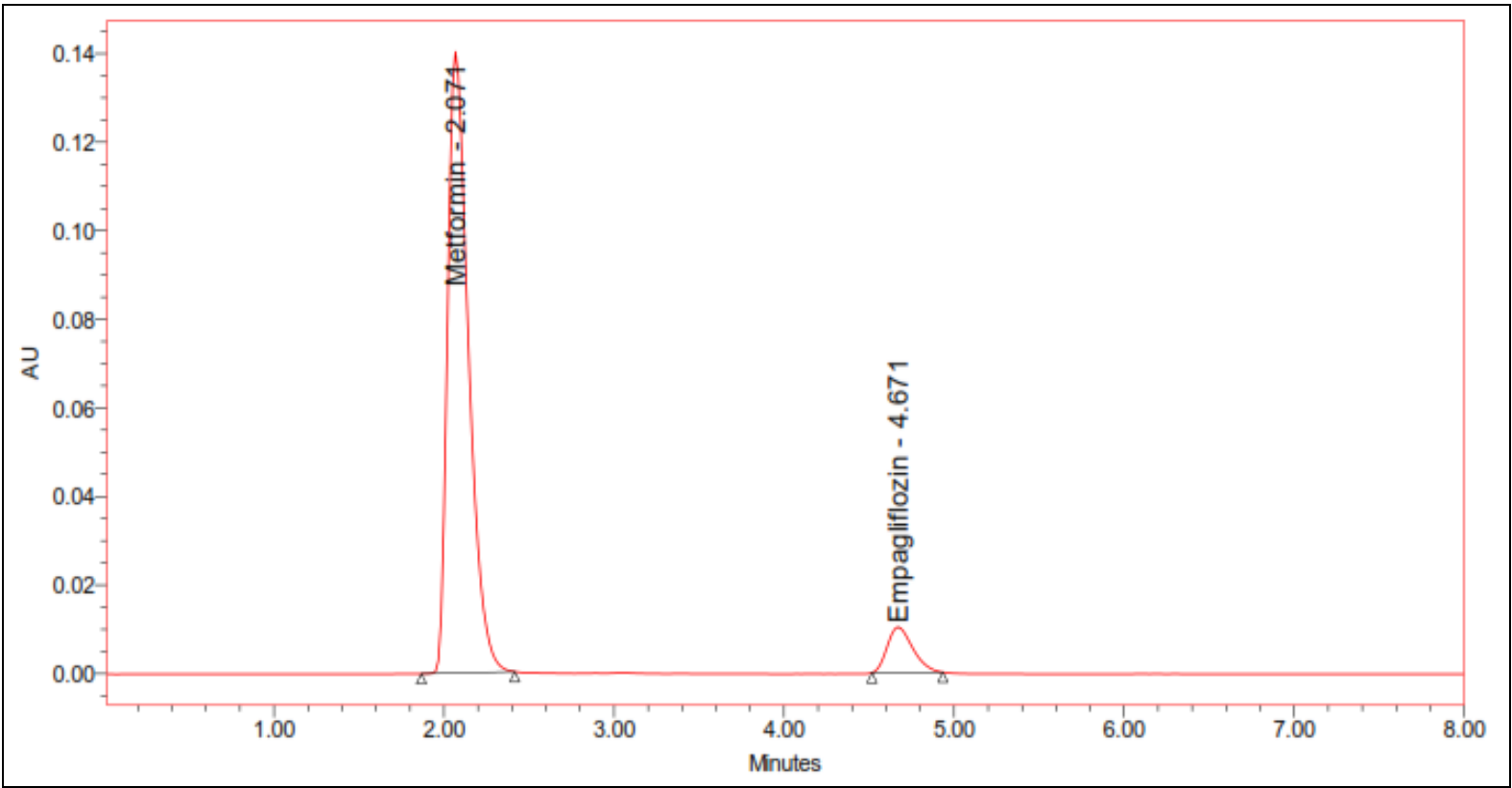

FIG. 12: CHROMATOGRAM SHOWING LESS ORG

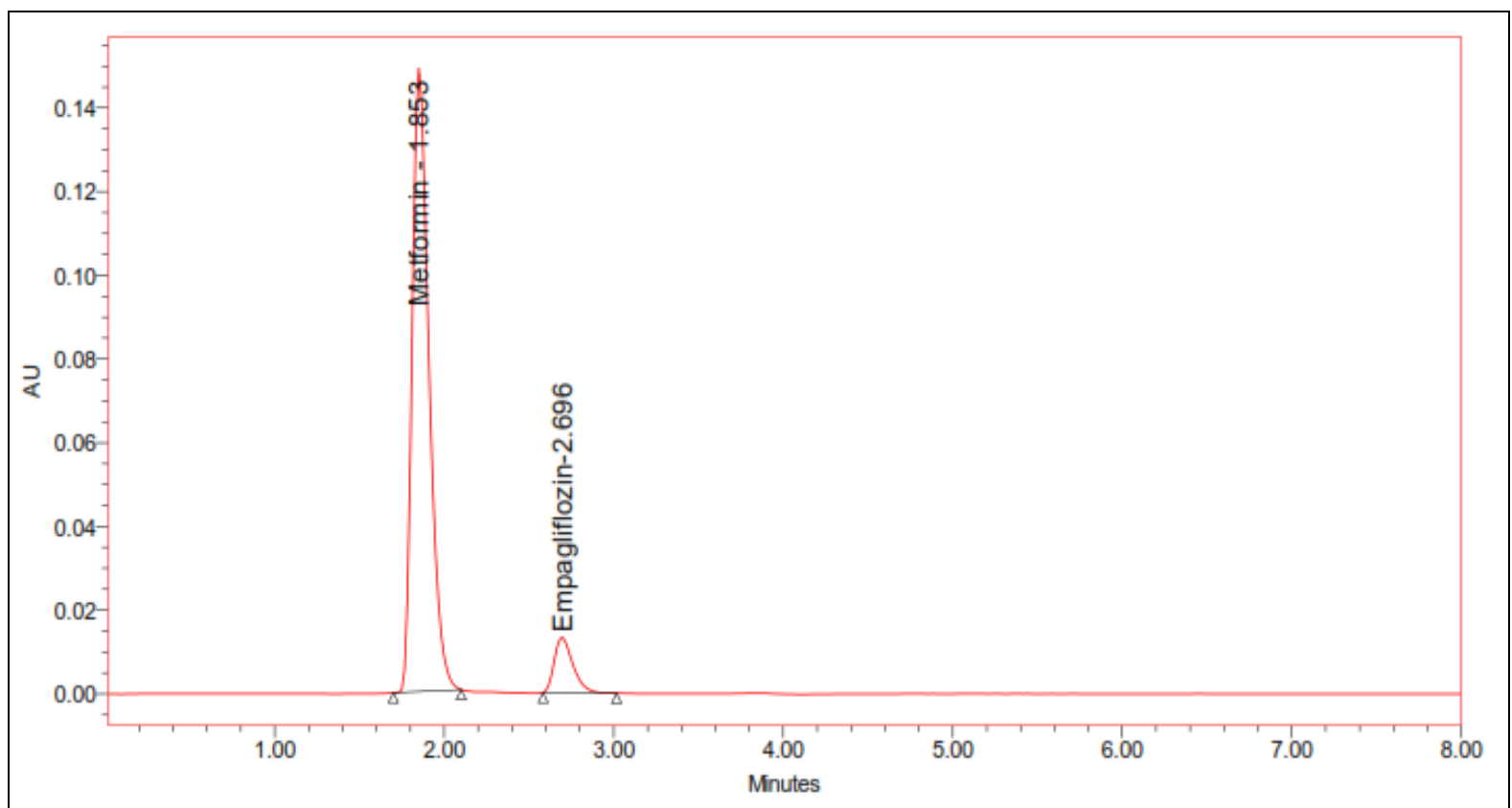

FIG. 13: CHROMATOGRAM SHOWING MORE ORG

International Journal of Pharmaceutical Sciences and Research 
TABLE 10: SHOWING SYSTEM SUITABILITY RESULTS FOR METFORMIN

\begin{tabular}{cccc}
\hline S. no. & $\begin{array}{c}\text { Change in Organic } \\
\text { Composition in the Mobile } \\
\text { Phase }\end{array}$ & USP Plate Count & System Suitability Results \\
\cline { 3 - 4 } & $10 \%$ less & 2318.6 & USP Tailing \\
\hline 1 & *Actual & 2415.75 & 1.5 \\
2 & $10 \%$ more & 2563.0 & 1.43 \\
3 & & & 1.4 \\
\hline
\end{tabular}

TABLE 11: SHOWING SYSTEM SUITABILITY RESULTS FOR EMPOGLIFLOZ

\begin{tabular}{cccc} 
S. no. & $\begin{array}{c}\text { Change in Organic } \\
\text { Composition in the Mobile }\end{array}$ & \multicolumn{2}{c}{ System Suitability Results } \\
\cline { 3 - 4 } & Phase & USP Plate Count & USP Tailing \\
\hline 1 & $10 \%$ less & 4406.0 & 1.3 \\
2 & $*$ Actual & 3310.51 & 1.36 \\
3 & $10 \%$ more & 2775.5 & 1.4 \\
\hline
\end{tabular}

\section{Detection limit:}

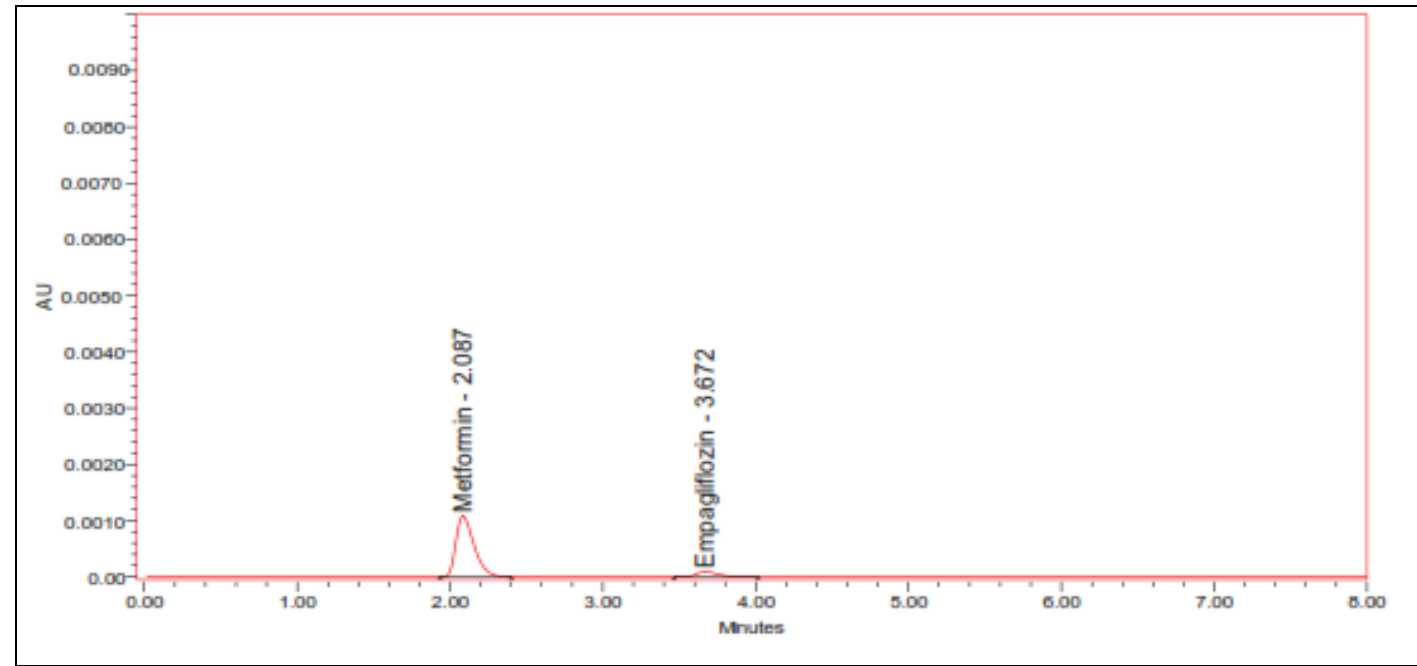

FIG. 14: CHROMATOGRAM SHOWING LOD

TABLE 12: SHOWING RESULTS FOR LIMIT OF DETECTION

\begin{tabular}{cccc}
\hline Drug name & Standard deviation $(\boldsymbol{\sigma})$ & Slope(s) & LOD $(\boldsymbol{\mu g})$ \\
\hline Metformin & 371827.90 & 563365963 & 2.17 \\
Empogliflozin & 5401.60 & 479884400 & 0.0372 \\
\hline
\end{tabular}

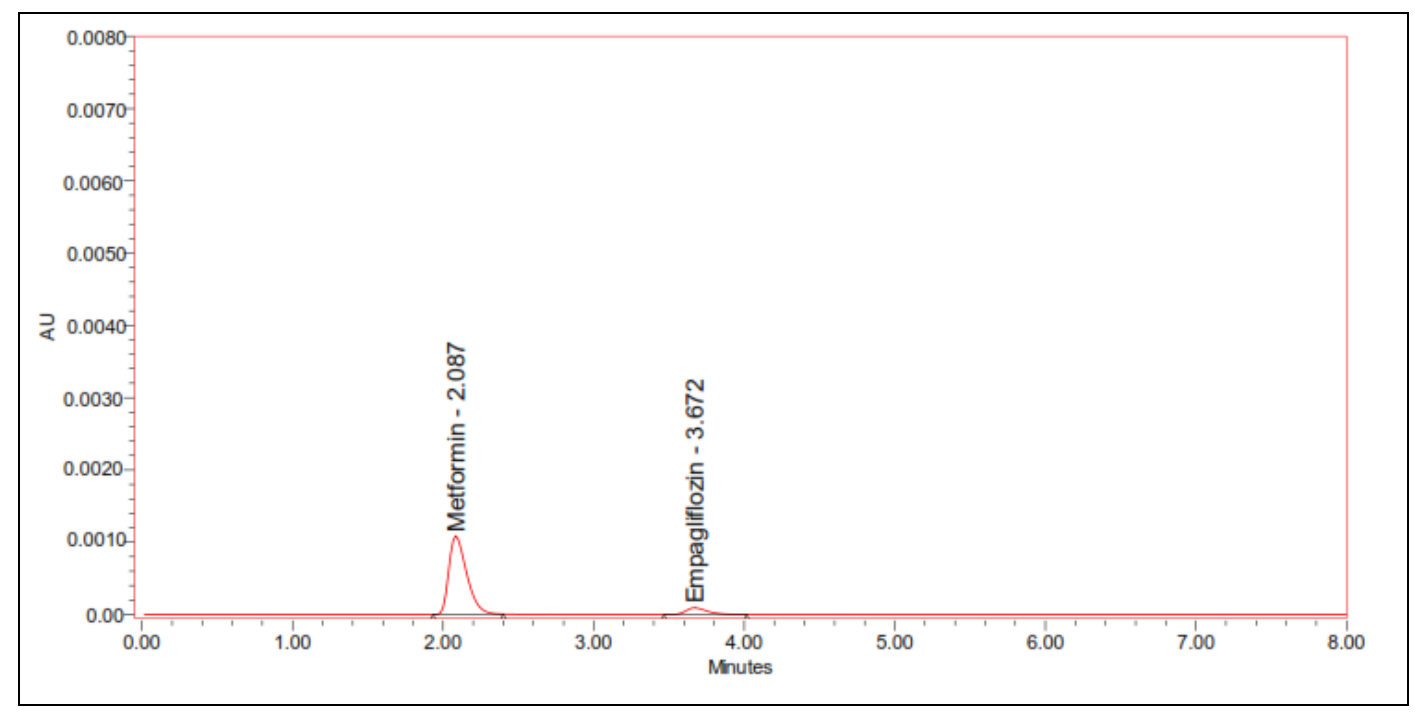

FIG. 15: CHROMATOGRAM SHOWING LOQ

International Journal of Pharmaceutical Sciences and Research 
TABLE 13: SHOWING RESULTS FOR LIMIT OF QUANTITATION

\begin{tabular}{ccc}
\hline Peak Name & RT & Area \\
\hline Metformine & 2.087 & 892474 \\
Empagliflozin & 3.672 & 87176 \\
\hline
\end{tabular}

CONCLUSION: The proposed HPLC method was found to be simple, precise, accurate and sensitive for the simultaneous estimation of Metformin and Empagliflozin in pharmaceutical dosage forms. Hence, this method can easily and conveniently adopt for routine quality control analysis of Metformin and Empagliflozin in pure and its pharmaceutical dosage forms. The new method developed and validated for Metformin and Empagliflozin in its bulk and tablets will help as a research interest to formulate different advanced drug delivery dosage forms and further its analyses.

ACKNOWLEDGEMENT: Authors are thankful to the Pharma Train Lab, Kukatpally, for providing instrumental and analytical support.

\section{REFERENCES:}

1. Grempler R, Thomas L, Eckhardt M, Himmelsbach F, Sauer A, Sharp DE, Bakker RA, Mark M, Klein T, Eickelmann P. "Empagliflozin, a novel selective sodium glucose cotransporter-2 (SGLT-2) inhibitor: characterisation and comparison with other SGLT-2 inhibitors". Diabetes Obes Metab, 2012, 14 (1), 83-90.

2. FDA (2015-05-15), SGLT2 inhibitors: Drug Safety Communication - FDA Warns Medicines May Result in a Serious Condition of Too Much Acid in the Blood". 2015.

3. "Metformin Hydrochloride". The American Society of Health-System Pharmacists. Retrieved Jan 2016.

4. Hirst JA1, Farmer AJ, Ali R, Roberts NW, Stevens RJ, Quantifying the effect of metformin treatment and dose on glycemic control, Diabetes Care, 2012 Feb, 35(2), 446-54.

5. Lilian Beatriz Aguayo Rojas, Marilia Brito Gomes., Metformin: an old but still the best treatment for type 2 diabetes. 2013

6. Arayne, M. SAEED, Najma Sultana, and M. HASHIM Zuberi, Development and validation of RP-HPLC method for the analysis of metformin, Pak J Pharm Sci, 2006, 19.3 231-5.

7. Shyamala, K. Nirmala, J. Mounika and B. Nandini, Validated stability-indicating RP-HPLC method for determination of Empagliflozin. Der Pharmacia Lettre, 2016, 8 (2), 457-464

8. Dnyaneshwar Thakare, Patil Vikas, Kalkotwar Ramesh, Jadhav Vijay, Chandra K Sekhar2, a new RP-HPLC method for simultaneous estimation of metformin HCL and linagliptin in tablet dosage form, 2013, 2(3), 13321341

9. Kavitha. K. Y, Geetha. G1, Hariprasad, Kaviarasu, Venkatnarayanan, Development and validation of stability indicating RP-HPLC method for the simultaneous estimation of linagliptin and metformin in pure and pharmaceutical dosage form. Journal of Chemical and Pharmaceutical Research, 2013, 5(1), 230-235

10. Pandya, Rutvik H., Rajeshwari Rathod, and Dilip G. Maheswari, Bioanalytical method development and validation for simultaneous determination of linagliptin and metformin drugs in human plasma by RP-HPLC method, Pharmacophore , 2014, 5(2), 202-218.

11. Sri, S. G., et al, A new RP-HPLC method development for simultaneous estimation of Metformin and Alogliptin in bulk as well as in pharmaceutical formulation using PDA detector, World J Pharm Pharm Sci, 2013, 6(2), 6720-43.

12. Ranetti, Maria-Cristina, et al, Validation of a HPLC method for the simultaneous analysis of metformin and gliclazide in human plasma, Farmacia, 2009, 57(6), 729. 735.

13. Modi, Darshana K, Punit B. Parejiya, Bhavesh H. Patel, A simple and sensitive HPTLC method for simultaneous determination of Metformin hydrochloride and Sitagliptin phosphate in tablet dosage form, Journal of Chemistry, 2013 (2012).

14. Srivani, Jillala, Balekari Umamahesh, Ciddi Veeresham, Development and Validation of stability indicating HPTLC method for simultaneous determination of linagliptin and metformin, International Journal of Pharmacy and Pharmaceutical Sciences, 2015, 8(1) 112115.

15. Jani, B. R., K. V. Shah, P. P. Kapupara, Development and Validation of UV spectroscopic method for simultaneous estimation of dapagliflozin and metformin hydrochloride in synthetic mixture.

16. Chirag, Amrita Parle, Development and validation of UV spectrophotometric method for simultaneous estimation of metformin hydrochloride and alogliptin benzoate in bulk drugs and combined dosage forms, Der Pharma Chemica, 2014, 6(1), 303-311

17. N. Padmaja, G. Veerabhadram , Development and validation of analytical method for Simultaneous estimation of Empagliflozin and Linagliptin in bulk drugs and combined dosage forms using UV-visible spectroscopy, Der Pharmacia Lettre, 2015, 7 (12), 306-312

18. Ayoub, Bassam M, UPLC simultaneous determination of empagliflozin, linagliptin and metformin, RSC advances, $2015,5.116$

How to cite this article:

Godasu SK and Sreenivas SA: A new validated RP-HPLC method for the determination of metformin HCL and empagliflozin in its bulk and pharmaceutical dosage forms. Int J Pharm Sci Res 2017; 8(5): 2223-32.doi: 10.13040/IJPSR.0975-8232.8(5).2223-32.

All @ 2013 are reserved by International Journal of Pharmaceutical Sciences and Research. This Journal licensed under a Creative Commons Attribution-NonCommercial-ShareAlike 3.0 Unported License.

This article can be downloaded to ANDROID OS based mobile. Scan QR Code using Code/Bar Scanner from your mobile. (Scanners are available on Google Playstore) 